\title{
CONSIDERAÇÕES ACERCA DA PROPRIEDADE PRIVADA À LUZ DA ANÁLISE ECONÔMICA DO DIREITO
}

\author{
Bianca de Paula Costa Lisboa Feitosa ${ }^{1}$ \\ Kátia Borges dos Santos ${ }^{2}$
}

Resumo: O artigo visa analisar que fatores a Análise Econômica do Direito - AED entende como relevantes no estudo da propriedade privada, posto que sua existência é determinante no desenvolvimento econômico das sociedades, para o exercício das liberdades individuais e da eficiente alocação de recursos. Analisar-se-á os fundamentos teóricos da AED, a abordagem econômica do direito de propriedade e por fim, suas restrições e seus mecanismos de proteção. Conclui-se pela relevância de sua aplicação aos direitos de propriedade enquanto fator relevante para a produção, circulação de riquezas e desenvolvimento. Na metodologia foi utilizado o método hipotético-dedutivo e da pesquisa bibliográfica.

Palavras-chave: Direito Econômico; Análise Econômica do Direito; Propriedade Privada; Restrições à Propriedade; Função Social da Propriedade.

\section{CONSIDERATIONS ABOUT PRIVATE PROPERTY IN LIGHT OF THE ECONOMIC ANALYSIS OF LAW}

\begin{abstract}
The article aims to analyze which factors the Economic Analysis of Law - AED understands as relevant in the study of private property, since its existence is crucial in the economic development of societies, for the exercise of individual freedoms and the efficient allocation of resources. The theoretical foundations of the AED, the economic approach property rights and, finally, their restrictions and protection mechanisms will be analyzed. It is concluded the relevance of its application to property rights as relevant factor for the production, circulation of wealth and development. The methodology was used the hypothetical-deductive method and the bibliographic research.
\end{abstract}

Keywords: Economic Law; Economic Analysis of Law; Private property; Property Restrictions; Social Function of Property.

\section{INTRODUÇÃO}

A pesquisa que aqui se propõe tem como objeto de análise os fatores que à luz da Análise Econômica do Direito são relevantes no estudo da propriedade privada.

\footnotetext{
${ }^{1}$ Mestranda em Direito, Políticas Públicas e Desenvolvimento Regional pelo Centro de Universitário do Estado do Pará - CESUPA. Pós-graduada em Direito Penal pela Damásio Educacional. Graduada em Direito pela Faculdade Ideal - FACI. Advogada. Endereço eletrônico: biancapclisboa@ gmail.com.

2 Mestranda em Direito, Políticas Públicas e Desenvolvimento Regional pelo Centro de Universitário do Estado do Pará - CESUPA. Pós-graduada em Direito Público e Processual Civil pela Estácio. Graduada em Direito pela Universidade Federal do Maranhão. Oficial de Registro de Imóveis no Estado do Pará. Endereço eletrônico: katiaborgess@hotmail.com.
}

Revista de Direito, Economia e Desenvolvimento Sustentável | e-ISSN: 2526-0057 | Belém | v. 5 | n. 2 | p. 56 - 71 | Jul/Dez. 2019. 
Os direitos de propriedade possuem um arcabouço jurídico bem definido na Constituição e na legislação infraconstitucional que norteiam o conteúdo axiológico esperado pelo ordenamento contemporâneo. No entanto, esse estudo propõe uma leitura para além da visão do texto legal e busca uma perspectiva interdisciplinar na Análise Econômica do Direito considerando a versatilidade dos direitos de propriedade e seu conteúdo, que não sendo necessariamente jurídico, pode assumir diversas feições.

Nesse sentido, a análise acerca da interação entre o Direito e a Economia torna-se relevante, nessa perspectiva. A Análise Econômica do Direito (Law and Economics) foi concebida na segunda metade do século passado, enquanto teoria que busca trazer ao direito ferramentas da microeconomia, a fim de subsidiar a criação de normas jurídicas e soluções concretas reguladas pela estabilidade, equilíbrio e busca de eficiência.

À luz dessas premissas, tem-se como objetivo do presente trabalho, alicerçado em um exercício hermenêutico pautado no subsídio teórico da Análise Econômica do Direito, analisar a propriedade privada enquanto instrumento apto a promover maior eficiência alocativa às atividades econômicas, equilíbrio de mercado, redução dos custos de transação e sobretudo - resultando num melhor cumprimento de sua função social.

O segundo tópico, estruturado através do método dedutivo, visa, compreender a teoria da Análise Econômica do Direito - AED, delineando sua origem e objeto, princípios e elementos estruturantes. No terceiro e último tópico, analisar-se-á a compreensão moderna da propriedade privada, seus contornos jurídicos, econômicos, formas de restrição e mecanismos de proteção. Por fim, depreende-se que o conteúdo normativo da propriedade privada muito além de sua legítima regulamentação deve ser entendido também como instituto a ser utilizado para servir de baliza para a congruência de elementos estruturantes que exigem a sociedade contemporânea marcada pela necessidade latente de desenvolvimento social e do mesmo modo econômico.

A metodologia utilizada será a da pesquisa bibliográfica qualitativa com o intuito de verificar os estudos efetuados na área e as condições de eficiência da propriedade privada à luz da análise da econômica do direito.

\section{ANÁLISE ECONÔMICA DO DIREITO}


A afinidade entre economia e direito já é fato conhecido pelo menos desde a discussão hobbesiana da propriedade, no século XVIII. No decorrer do século XX, as academias e estudiosos estadunidenses começaram a produzir material acadêmico em que se vislumbrava a aplicação na seara jurídica dos termos interdisciplinares da economia.

Ademais, para esses teóricos a teoria econômica pode demonstrar a ineficiência de algumas medidas e decisões, esclarecendo o conflito de valores e o custo de uma opção em detrimento de outra, bem como os meios através dos quais, eficientemente, uma coletividade pode solucionar seus problemas, alcançando-se uma política legislativa e judiciária eficientes.

Em meados do século XX (Filho, 2016, p. 213) alguns teóricos, como Aaron Director, Ronald Coase, Guido Calabresi, Gary Stanley Becker e Richard Allen Posner concretizaram o domínio da Análise Ecocômica do Direito, conhecida também pelo termo Law and Economics. Um dos objetivos da Análise Ecocômica do Direito (AED) é propor um estudo entre os diversos ramos do direito, com influência e contribuições da economia com vistas a melhorar a compreensão dos fenômenos sociais e suas consequências econômicas no direito. Gico Jr. define a Análise Ecocômica do Direito como:

Campo do conhecimento humano que tem por objetivo empregar variadas ferramentas teóricas e empriricas econômicas e das ciências afins para expandir a compreensão e o alcance do direito e aperfeiçoar o desenvolvimento, a aplicação e a avaliação de normas jurídicas, principalmente com relação às suas consequências (GICO JR., 2018, p. 04).

Assim, em 1973 com a publicação do Economic Analysis of Law, de Richard A. Posner se consolidou o movimento da Análise Econômica do Direito, em que a aplicação de critérios de eficiência para a análise do direito traria uma margem mais segura de isonomia das decisões judiciais. Para tanto, quanto ao estudo da teoria, o enfoque econômico do sistema jurídico pressupõe uma compreensão e interpretação da legislação com vistas a direcionar as decisões a um racional aproveitamento dos recursos.

Nesse sentido, Posner (2005, p. 8) diz que os objetivos da AED possuem aspectos não apenas normativos mais descritivos, a análise econômica do direito possui tanto aspectos positivos (isto é, descritivos) quanto aspectos normativos. Seu objetivo é tentar explicar e prever o comportamento dos grupos que participam do sistema jurídico, além de explicar a estrutura doutrinal, procedimental e institucional do sistema. Mas também busca aperfeiçoar o direito, ao assinalar as consequências involuntárias ou indesejáveis das leis vigentes ou dos projetos de lei e propor reformas práticas. 
Richard Posner (2007, p. 40) sugere que os recursos valiosos têm de observar, cumulativamente, os critérios de universalidade, exclusividade e transferência, o que teria o condão de maximizar seu valor. $\mathrm{Na}$ aplicação da AED ao sistema jurídico existe a maximização da riqueza quando os bens e recursos estão na posse de quem os valoriza, e por seu turno dos que estão dispostos a arcar com os custos de valor para deter os mesmos.

O pensamento institucionalista ganhou esboço com os ensinamentos de Ronald Coase (1960, p. 44), ao afirmar que os direitos de propriedade devem ser bem definidos para superar as externalidades presentes no mercado, mesmo não sendo ilimitados. A definição de eficiência da propriedade, bem como a (i)rrelevância dos direitos legais de propriedade, dependerá, portanto, à luz do Teorema de Coase, do nível dos custos de transação. Para Jianlin (2013, p. 2), o Teorema de Coase "has profoundly altered the paradigm of legal theory while laying the foundation for the law \& economics movement". De modo que, até os dias atuais é utilizado como parâmetro eficaz de abordagem econômica.

Longe de esgotar o estudo, Vera (In TIMM, 2018, p. 224), ressalta que as ferramentas da economia tem relevante uso e "com a ajuda das teorias da negociação, da escolha pública (Public Choice) e do estudo das externalidades, a disciplina Direito e Economia proporciona ferramentas e um método que viabilizam uma análise coerente, ordenada e científica" da propriedade, o resultado é um embasamento teórico que auxilia o país a desenvolver estruturas produtivas e instituições sólidas, onde a garantia dos direitos de propriedade é um dos preceitos básicos de crescimento econômico.

A aplicação de parâmetros econômicos pela AED na solução de litígios em decisões judiciais sofreu críticas de outros teóricos a exemplo de Dworkin (Rendeiro, p. 114) ao afirmar que a aplicação da maximização da riqueza social, como objetivo digno é falha, na medida em que não restam esclarecidos os motivos de sua valoração enquanto fim. Para Dowkin, a riqueza social não pode ser um componente de valor, e o dinheiro apenas pode ser considerado útil quando pode proporcionar ao indivíduo uma vida mais valiosa, bem-sucedida e feliz.

Em que pese as críticas que lhes foram apontadas, as contribuições da AED propiciam vetor para que o direito de propriedade possa ser reconhecido, para fins econômicos, como feixe de direitos e, pois, igualmente de deveres. Diante da finitude de recursos e da perenidade de interesses, faz-se necessário (re)alocar direitos de propriedade a

\section{Revista de Direito, Economia e Desenvolvimento Sustentável | e-ISSN: 2526-0057 | Belém | v. 5 | n. 2 | p. 56 - 71 | Jul/Dez. 2019.}


fim de que estes permaneçam nas mãos dos que têm melhores condições de valorizá-los - e, por evidente, condição de pagamento - para que, com isto, se construa a eficiência perquirida.

Ainda que a proximidade de estudo entre direito e economia tenham surgido em primeiro plano em uma comunidade jurídica de tradição do common law, sua aplicação enquanto norteadora de decisões judiciais que maximizam o bem-estar econômico pode e deve ser aplicada de forma interdisciplinar, é o que restará ilustrado a seguir, com a abordagem econômica dos direitos relacionados à propriedade privada.

\section{ANÁLISE ECONÔMICA DA PROPRIEDADE}

O conceito de propriedade é complexo e gera uma gama extremamente diversificada de direitos e relações para o direito. Na lei brasileira a propriedade tem uma estrutura legalmente codificada. Essa estrutura pode não ser simples ou clara o suficiente para satisfazer os critérios econômicos. Mas, sua normatividade é inteligível, estando aberta à ideia de que as estruturas dos conceitos sociais podem acompanhar a estrutura dos artefatos institucionais e dos movimentos sociais que estão em constante transformação. A Constituição atual quebrou os remotos vetores patriarcais e individualistas e, democraticamente, não hesitou em afirmar a vontade constitucional de assegurar a inviolabilidade do direito à propriedade e a garantia do direito de propriedade como um dos princípios fundamentais da ordem econômica ${ }^{3}$.

A propriedade é organizada em primeira instância em torno de três conceitos (Claeys, 2018, p. 39): um conceito de propriedade como um campo de organização social e legal, outro para relações chamadas de direitos de "propriedade" e um para relações proprietárias chamadas de "direitos".

\footnotetext{
${ }^{3}$ Art. $5^{\circ}$, caput, CRFB. Todos são iguais perante a lei, sem distinção de qualquer natureza, garantindo-se aos brasileiros e aos estrangeiros residentes no País a inviolabilidade do direito à vida, à liberdade, à igualdade, à segurança e à propriedade, nos termos seguintes.

Art. $5^{\circ}$, XXII, CRFB. Todos são iguais perante a lei [...]: XXII - é garantido o direito de propriedade.

Art. 170, II, CRFB. A ordem econômica, fundada na valorização do trabalho humano e na livre iniciativa, tem por fim assegurar a todos existência digna, conforme os ditames da justiça social, observados os seguintes princípios: II - propriedade privada.

Art. $5^{\circ}$, XXII, CRFB. Todos são iguais perante a lei [...]: XXIII - a propriedade atenderá a sua função social.

Art. 170, III, CRFB. A ordem econômica [...] observados os seguintes princípios: III - função social da propriedade.
} 
Nessa abordagem nos referimos ao sentido que é empregado pelos "direitos de propriedade" ao uso racional e adequando, economicamente analisado, à propriedade física, local de abrigo, uso, costumes e construção de relações sociais entre os indivíduos, quer individualmente, quer coletivamente. Nesse sentido, Vera (2018. p. 201) ressalta que a análise econômica do direito de propriedade é uma das primeiras áreas de estudo da disciplina Direito e Economia, considerando que a partir da regulação do direito de propriedade a sociedade reconhece que um certo bem pertence a um de seus membros e como seu direito de uso está definido.

Para North (1991, p. 97) as "institutions provide the incentive structure of an economy; as that structure evolves, it shapes the direction of economic change towards growth, stagnation, or decline ${ }^{4}$. Assim, as instituições exercem ao longo da história influência na determinação de políticas econômicas, e um mercado de capitais é estável quando traz a segurança dos direitos de propriedade ao longo do tempo ${ }^{5}$. O conceito-chave para o entendimento de prosperidade proposto por North é o de instituições eficientes. Para o autor:

Efficient organization entails the establishment of institutional arrangements and property rights that create an incentive to channel individual economic effort into activities that bring the private return close to the social rate of return (NORTH e THOMAS, 1973, p. 1).

Não se pode dissociar a ideia de que os mercados definem o ritmo das economias e o estabelecimento econômico das nações. Nesse sentido, é primordial que um feixe seguro de direitos de propriedade esteja assegurado e previamente estabelecido. Como sugerido por Cooter e Ulen (2010, p. 92) é indispensável uma definição clara dos direitos de propriedade, considerando sua dupla funcionalidade: a de alocar recursos e com isso promover sua distribuição eficiente. Mesmo que a ciência do direito, por suas normas legais, não detenha todas as respostas aos conflitos e necessidades sociais, a esse sistema se espera um norte de proteção quando as relações de mercado não puderem se manter pacificamente.

\subsection{Restrições ao direito da propriedade}

\footnotetext{
${ }^{4}$ As instituições fornecem a estrutura de incentivo de uma economia; o modo como a estrutura evolui, molda a direção da mudança econômica em direção ao crescimento, estagnação ou declínio (NORTH, 1991, p. 97, tradução nossa).

5 “A capital market entails security of property rights over time and will simply not evolve where political rulers can arbitrarily seize assets or radically alter their value” (NORTH, 1991, p. 101).
} 
Como agente normativo e regulador da atividade econômica, o Estado exercerá, na forma da lei, as funções de fiscalização, incentivo e planejamento, sendo este determinante para o setor público e indicativo para o setor privado, nos termos do artigo 174 da Constituição Federal. Dentre as medidas que podem ser adotas pelo Estado com o fim de promover o desenvolvimento econômico está o incentivo às atividades que gerem ganhos e movimentem a economia. Assim, o artigo 153, I, da Constituição Federal diz que: Compete à União instituir impostos sobre a propriedade territorial rural, e que esse imposto será progressivo e terá suas alíquotas fixadas de forma a desestimular a manutenção de propriedades improdutivas.

O artigo 156 adiante, prevê que compete aos Municípios instituir impostos sobre a propriedade predial e territorial urbana, sem prejuízo da progressividade no tempo a que se refere o art. 182, $\S 4^{\circ}$, inciso II, de modo que o imposto territorial urbano poderá ter alíquotas diferentes de acordo com a localização e o uso do imóvel. Dentre essas medidas fiscais com fins de desestimular a manutenção de propriedades improdutivas como instrumento de ordenação socioeconômica do direito de propriedade, o ordenamento pátrio prevê que o Estado intervirá na propriedade caso não se cumpra a sua função sócio-econômico-ambiental, de igual modo quando houver descumprimento da proibição da utilização da posição jurídica proprietária com o intento deliberado de prejudicar terceiros.

O artigo 243 da Constituição reza que as propriedades rurais e urbanas de qualquer região do País onde forem localizadas culturas ilegais de plantas psicotrópicas ou a exploração de trabalho escravo na forma da lei serão expropriadas e destinadas à reforma agrária e a programas de habitação popular, sem qualquer indenização ao proprietário e sem prejuízo de outras sanções previstas em lei, observado, no que couber, o disposto no art. $5^{\circ}$. Ainda em relação aos meios de intervenção do Estado na propriedade a Constituição dispõe em seu artigo 185 que são insuscetíveis de desapropriação para fins de reforma agrária: - a pequena e média propriedade rural, assim definida em lei, desde que seu proprietário não possua outra; e - a propriedade produtiva. Determina ainda que a lei garantirá tratamento especial à propriedade produtiva e fixará normas para o cumprimento dos requisitos relativos à sua função social.

A legislação infraconstitucional prevê no Código Civil o instituto da servidão predial e disposições no direito de vizinhança que geram restrições ao uso da propriedade privada. No 
mesmo diploma, o artigo 1.228, disciplina que o proprietário tem a faculdade de usar, gozar e dispor da coisa, e o direito de reavê-la do poder de quem quer que injustamente a possua ou detenha, e que a ele são defesos os atos que não trazem qualquer comodidade, ou utilidade, e sejam animados pela intenção de prejudicar outrem.

Assim, mostra-se oportuno a estipulação de um conteúdo mínimo de direitos da propriedade. Vera (2018. p. 201) cita a cientista Elinor Ostron, laureada com Prêmio Nobel de Economia, que elencou cinco direitos de propriedade principais: - acesso ao bem; - retirada do uso; - a gestão do uso; - a exclusão e a - alienação. Nestes, estabelece-se um conteúdo mínimo de direitos de propriedade, determinando, por conseguinte, consequências nas relações sociais e econômicas. Dentro dos critérios de gestão e uso, estão inseridos nos direitos de propriedade, a função social da propriedade enquanto orientação a ser seguida quanto ao modo de uso e gestão dos recursos inerente à propriedade seja ela urbana ou rural.

Adiante, a ver-se-á que critérios são utilizados para se auferir o atendimento à função social da propriedade, com vistas a autorizar a intervenção do Estado em seu domínio, seja com medidas fiscais ou de desapropriação, caso a mesma não preencha os requisitos legais exigidos.

\subsubsection{Função social da propriedade}

A função social da propriedade, encontra-se disciplinada nos arts. $5^{\circ}$, inciso XXIII, 170, inciso III, e 184 da Constituição Federal e sua aplicação costuma gerar calorosas discussões em virtude de sua natureza filosófica e abstrata e a dificuldade de correlação com a garantia do direito de propriedade privada, que também é direito fundamental.

Hoje, entretanto, o direito de propriedade se apresenta, indelevelmente, comprometido com o uso responsável desta, segundo cumprimento de sua função social. Para Vaz (1993) a função social é inerente à propriedade.

A função social da propriedade igualmente pode ser vista à luz do princípio da eficiência econômico-social, já que é um meio de distribuição e redistribuição dos recursos escassos segundo o mínimo ético legal estipulado pelo Estado. Ademais, o exercício da função social, desde que seu conceito esteja bem definido, viabiliza a redução dos custos de transação, eis que garante o direito de propriedade, condição essa necessária à eficiência da alocação de recursos em conformidade com o Teorema de Coase, Coase (1960, p. 40). 
A propriedade, no entendimento segundo a AED, passa a cumprir sua função social, na medida em que gera riqueza e de forma eficiente, o que, não essencialmente implica igualdade na distribuição daquela.

Segundo a legislação brasileira, a propriedade rural atende sua função social quando nos termos do artigo 186 da Constituição Federal a propriedade rural atende, simultaneamente, segundo critérios e graus de exigência estabelecidos em lei, aos seguintes requisitos, sendo eles: I - aproveitamento racional e adequado; II - utilização adequada dos recursos naturais disponíveis e preservação do meio ambiente; III - observância das disposições que regulam as relações de trabalho e, IV - exploração que favoreça o bem-estar dos proprietários e dos trabalhadores. Frise-se que a legislação pátria prevê que os critérios sejam atingidos de forma simultânea, ou seja, que sejam todos os critérios sejam preenchidos a um só tempo, para que então se configure a função social da propriedade rural ali descrita.

Assim, a legislação indica, pois, que o uso racional de uma propriedade está intimamente ligado com sua exploração maximizadora de resultados - eficiência produtiva; não se admitindo, portanto, a estagnação da riqueza, e justifica que os processos de expropriação e redistribuição da propriedade estejam direcionados às mãos de quem produz.

Enquanto os requisitos apenas numéricos de satisfação do critério de produção forem levados em conta, quando da avaliação dos requisitos para ser ter a plenitude da função social da propriedade não estaremos adotando critérios de eficiência econômica para se afirmar que uma propriedade é ou não produtiva. Nesse sentido, Vera ressalta:

A disciplina Direito e Economia tem muito a dizer sobre o conceito de produtividade. De forma geral, a legislação aplica tal conceito de produtividade baseado apenas no único fator de produção por quantidade de terra (hectare) (VERA, 2018, p. 214).

Impor limitações, restrições administrativas ao uso da propriedade, usando como critério a produtividade conforme está disposta no artigo $6^{\circ}$ da Lei $n^{\circ} 8.629 / 1993$, é caminhar na contramão da dinâmica social que exige que uma propriedade seja eficiente não apenas em produtividade, mas também social, econômica e ambientalmente. Nesse sentido, acerca dos graus de intervenção na propriedade:

Current literature highlights the disadvantages, misuse, and drawbacks of private property and moves in the opposite direction: that is, advocating limitations on private property and calling for less protection of individuals against state intervention. The "too much property" claim is applied in many

Revista de Direito, Economia e Desenvolvimento Sustentável | e-ISSN: 2526-0057 | Belém | v. 5 | n. 2 | p. $56-71$ | Jul/Dez. 2019. 
contexts, with varying degrees of persuasion and success ${ }^{6}$ (LEWINSOHNZAMIR, 2001, p. 99).

Por seu turno, a propriedade urbana atende critérios de utilização com vistas a sua função social quando atende aos requisitos do artigo 182, § $2^{\circ}$ da Constituição Federal: “A propriedade urbana cumpre sua função social quando atende às exigências fundamentais de ordenação da cidade expressas no plano diretor”. Em relação a propriedade urbana a norma constitucional deixa a cargo dos planos diretores, que são de iniciativa das gestões municipais, definir critérios locais que levem em consideração da dinâmica das cidades em cada região do país.

\subsection{Mecanismos de proteção da propriedade privada}

Nos estudos da análise econômica do direito, acerca do direito de propriedade, Posner (2007, p. 143) acredita que o mercado é o maior e mais eficiente meio de se determinar o direito com vista ao uso eficiente dos recursos. A propriedade privada é uma ferramenta importante para maximizar a riqueza total, porque assegura o aproveitamento de ativos a longo prazo e protege contra futuras dores e perdas.

Com a definição clara dos detentores da propriedade, há maior maximização das riquezas e bem-estar, uma vez que o bem escasso estará sendo utilizado de forma mais rentável, racional e, portanto, eficiente. Sobre essa questão, Richard Posner ressalta que:

Con "maximización de la riqueza" quiero indicar la política de intentar maximizar el valor agregado de todos los bienes y servicios, ya sea que se comercien en mercados formales (los bienes y servicios "econômicos" usuales) o (en el caso de bienes y servicios "no-económicos", como la vida, la recreación, la família y la libertad de dolor y sufrimiento) que no se comercien em tales mercados ${ }^{7}$ (POSNER, 2019, p. 24).

Quando os direitos de propriedade estão ausentes, os frutos de o trabalho e o investimento de uma pessoa podem ser forçosamente tomados por outras pessoas. Resultados de produtividade negativos resultariam, em não alocação de recursos para a subsistência da

\footnotetext{
6 "A literatura atual destaca as desvantagens e o uso indevido da propriedade privada e movimentos na direção oposta: isto é, advogar limitações à propriedade privada e pedindo menos proteção dos indivíduos contra a intervenção do Estado. O sentido de "mais propriedade" é aplicada em muitos contextos, com vários graus de persuasão e sucesso" (LEWINSOHN-ZAMIR, 2001, p. 99, tradução nossa).

7 Com a "maximização da riqueza", quero indicar uma política de tentar maximizar o valor agregado de todos os bens e serviços, sejam eles negociados em mercados formais (os bens e serviços "econômicos" usuais) ou (no caso de bens e serviços), e de serviços "não-econômicos", como a vida, a recreação, a família e a liberdade, da dor e do sofrimento que não são negociados nesses mercados (POSNER, 2019, p. 24, tradução nossa).
}

Revista de Direito, Economia e Desenvolvimento Sustentável | e-ISSN: 2526-0057 | Belém | v. 5 | n. 2 | p. 56 - 71 | Jul/Dez. 2019. 
produção, que requerem muito investimento. Isso seria prejudicar o crescimento da sociedade. Além disso, os direitos de propriedade alcançam internalização de externalidades e evitam o uso ineficiente desses recursos.

Os feixes de direitos de propriedade centram-se em regras específicas que podem ser derivadas de justificativas econômicas, que envolve questões como a indenização por danos à propriedade, indenização pela desapropriação e impostos progressivos pela improdutividade, entre outros. A compensação pode ser necessária porque uma constante ou generalizada prática de não compensação causaria desmoralização de seu uso e ineficiência a longo prazo. O mesmo ocorre na definição de ser ou não improdutiva economicamente.

A propriedade privada é justificada pela análise econômica precisamente porque na propriedade privada ausente, as pessoas investiriam muito pouco em ativos, temendo que outros possam forçosamente levar os frutos de tal investimento. Os direitos de propriedade são concedidos para incentivar as pessoas a investirem em ativos acima do nível de investimento que elas teriam escolhido caso não houvesse proteção. Em outras palavras, há interesse que as pessoas invistam em terra, por exemplo, com o conhecimento de que elas serão protegidas no futuro pelas suas aquisições, e serão compensadas, caso esse feixe direitos e aquisições estejam ameaçados.

A propriedade enquanto instituição que fomenta a atividade econômica e é veículo de maximização de riquezas não pode ser vista como "coisa" e sim como um "pacote de direitos". Há a necessidade de se visualizar a propriedade não como uma coisa física ou legal para visualizá-la como um conjunto de direitos numerosos e distintos. Nesse sentido, Vera (2011, p. 9) destaca uma agenda mínima de medidas que garantam proteção à propriedade e visam conferir incentivos ao empreendedorismo e, por conseguinte ao crescimento da nação.

Primeiro, uma compatibilização dos direitos fundamentais de garantia da propriedade privada e o da função social da propriedade tanto via legislação, com normas claras, uniformização de jurisprudência, de forma a minimizar os prejuízos decorrentes de uma falta de previsibilidade e insegurança jurídica, principalmente no meio rural. Segundo, mais eficiência da proteção à posse, como no caso do instituto da reintegração de posse. Ainda que a posse e propriedade sejam institutos jurídicos diferentes, a proteção da posse acaba sendo na prática uma forma de se proteger a propriedade e de blindar investimentos de ataques feitos por organizações com propósitos ideológicos. Terceiro, há uma necessidade de 
revisão do conceito de produtividade da Lei n 8.629, de 1993, Lei da Reforma Agrária, uma vez que não reflete o dinamismo do conceito de eficiência e desapropria ou deixa de desapropriar terras, por atingir resultados muitas vezes equivocados;

Mais adiante, faz-se oportuno repensar o conceito de "prévia e justa indenização" no caso de desapropriações de imóveis rurais, nos termos do artigo 184 da Constituição, que prevê o pagamento em títulos da dívida agrária, com cláusula de preservação do valor real, resgatáveis no prazo de até vinte anos, a partir do segundo ano de sua emissão.

Sem entrar no mérito do que é uma justa indenização, para Vera (2011, p. 10) as transferências involuntárias de propriedades provocadas pelo Estado são caras e geralmente trazem distorções ao mercado e uma redução na produção.

As indenizações, mesmo que a preço de mercado, correm o risco de não refletirem o valor subjetivo da propriedade e causam distorções no mercado. No entanto, indenizações em dinheiro distorcem menos o mercado e desestimulam o governo a desapropriar apenas para atingir metas gerais ou para atender interesses restritos de pequenos grupos.

Há a necessidade de se manter e colocar em discussão aberta os dados sobre desapropriações e assentamentos, para que a sociedade tenha conhecimento e possa debater os resultados dessa política pública agrária de distribuição de terras.

Por fim, um estabelecimento juridicamente seguro dos direitos de propriedade, e que quem detém os direitos de dono, desse modo, ao se instituírem os proprietários dos bens, há utilização mais eficiente, mais raciona, e mais duradoura dos recursos, essa sendo a cerne da AED acerca dos direitos de propriedade.

O que se busca ao fim, é que as transações que envolvam os direitos de propriedade tenham os custos reduzidos a fim de não justificar uma interferência Estatal, e que as instituições sejam mais eficientes na medida que dispõem de direitos de propriedade mais nítidos e cristalinos, que se farão necessários caso a iniciativa negocial falhe ou não conceba o deslinde almejado.

\section{CONCLUSÃO}

Dessa forma, tem-se que o direito à propriedade privada previsto no ordenamento jurídico do brasileiro é compatível, de um modo geral, com uma abordagem conforme a análise econômica do direito, bem como com os aspectos a ela inerentes, delimitar 
normativamente, o ambiente institucional do mercado com vistas a corrigir falhas, e, pois, trazer mecanismo à norma jurídica de interação com outros ramos interdisciplinares, e assim, sempre que a negociação entre as partes se mostrar ineficiente, ou se demonstrar altos custos de transação, o direito seria acionado para tutelar os direitos de propriedade.

Portanto, em qualquer caso de atribuição ou proteção aos direitos de propriedade, que terá reflexo imediato para seu detentor, e, para a sociedade de forma irradiada como um todo, deve-se ponderar qual a forma mais eficiente de se alocar esses recursos. Em um primeiro momento, a propriedade foi alocada e historicamente distribuída. No entanto, a dinâmica dos mercados modernamente exige que seu uso seja atingido com um critério acentuado, o da eficiência.

As condições e restrições impostas ao uso da propriedade privada, em sua abordagem econômica, são exceção e não a regra. As limitações administrativas e as desapropriações motivadas pelo interesse, necessidade e função social, devem delimitar e compreender em que contexto estão sendo inseridos os critérios de efetividade econômica na avaliação do uso racional e adequado da propriedade que atende à sua função social. Ao que a legislação indica, esses critérios são apenas quantitativos.

Tem-se uma agenda urgente nos países em desenvolvimento de se conferir aos detentores da propriedade mecanismos de proteção que reforcem seu uso de forma economicamente eficiente. Esperar do arcabouço jurídico todas as respostas para se conferir à propriedade uso adequado e economicamente satisfatório não é a saída.

Resta por fim, inegável a relação entre os direitos de propriedade e a análise econômica do direito, tendo em vista ser economicamente mais eficiente se delimitar, previamente, quem é(são), exatamente, o(s) proprietário(s) de determinado bem escasso, e para além disso, se estabelecer critérios não apenas normativos acerca de seu uso e de suas limitações, mas, não menos importantes, critérios economicamente viáveis e eficientes, para se auferir a função econômico-social da propriedade enquanto agente ativo na geração de riquezas e de crescimento econômico. E, que os direitos de propriedade, sob essa ótica possam ser reconhecidos, para fins econômicos, como um feixe de direitos e igualmente de deveres.

\section{REFERÊNCIAS}

Revista de Direito, Economia e Desenvolvimento Sustentável | e-ISSN: 2526-0057 | Belém | v. 5 | n. 2 | p. 56-71 | Jul/Dez. 2019. 
BENTHAM, Jeremy. Uma introdução aos princípios da moral e da legislação. Tradução de Luiz João Baraúna. São Paulo: Abril, 1974.

BRASIL. Constituição (1988). Constituição da República Federativa do Brasil. Brasília: Senado Federal, 2019.

COASE, Ronald H. The problem of social cost. The Journal of Law and Economics, v. 3, p. 1-44, 1960. Disponível em: https://www.heinonline.org. Acesso em: 28 jun. 2019.

COOTER, Robert; ULEN, Thomas. Direito e Economia. Porto Alegre: Bookman, 2010.

COOTER, Robert; ULEN, Thomas. Law and Economics. 6. Ed. Berkeley Law Books, 2016. Disponível em: http://scholarship.law.berkeley.edu/books/2. Acesso em 13 ago. 2019.

CLAEYS, Eric R. Use and the Function of Property. The American Journal of Jurisprudnce, v. 63, n. 2, p. 221-258, 2018. Disponível em: https://www.heinonline.org. Acesso em: 28 jun. 2019.

—, Ronald H. O problema do custo social. Disponível em: http://www.pucpr.br/arquivosUpload/5371894291314711916.pdf. Acesso em: 11 jul. 2019.

COMPARATO, Fábio Konder. Direitos e deveres fundamentais em matéria de propriedade. In Revista do Ministério Público do Estado do Rio de Janeiro, n. 7, p. 73-88, 1998.

DEMSETZ, Harold. Hacia Una Teoria de Los Derechos de Propriedad. Disponível em: http://www.eumed.net/cursecon/textos/Demsetz_teoria-derechos-propiedad.pdf. Acesso em: 20 jun. 2019.

DWORKIN, Ronald. Levando os direitos a sério. Trad. Nelson Boeira. São Paulo: Martins Fontes, 2002.

FILHO, Sírio Vieira dos Santos. A eficiência sob a perspectiva da análise econômica do direito Justiça do Direito. v. 30, n. 2, p. 210-226, 2016.

GICO JR, Ivo. Introdução ao Direito e Economia. In: TIMM, Luciano Benetti. Direito e economia no Brasil. São Paulo: Atlas, 2018.

GONÇALVES, Everson das Neves. A teoria de Posner e sua aplicabilidade à ordem constitucional econômica brasileira de 1988. 1997. Dissertação (Mestrado em Direito) Universidade Federal de Santa Catarina, Florianópolis, 1997.

JIANLIN, Chen. The Coase Theorem, Richard A. Posner and Francisco Parisi. 43 HONG KONG L.J. 1083 (2013). Disponível em: https://www.heinonline.org. Acesso em: 28 jun. 2019. 
LEWINSOHN-ZAMIR, Daphna. Contemporary Property Law Scholarship: A Comment, 2 THEORETICAL INQ. L. 97 (2001). Disponível em: https://www.heinonline.org. Acesso em: 28 jun. 2019.

MACKAAY. Ejan; ROUSSEAU, Stephane. Análise econômica do direito. Tradução: Rachel Sztajn. São Paulo: Atlas, 2015.

MERCURO, Nicholas; MEDEMA, Steve G. Economics and the law - from Posner to postmodernism. Princeton/New Jersey: Princeton University Press, 1999.

NORTH, Douglass C. Institutions. The Journal of Economic Perspectives, v. 5, n. 1. Winter: 1991, pp. 97-112. Disponível em: https://www.heinonline.org. Acesso em: 28 jun. 2019.

THOMAS, Robert Paul. The rise of the western world: a new economic history. Cambridge: Cambridge University Press, 1973, p. 1. Disponível em: https://www.heinonline.or g. Acesso em: 28 jun. 2019.

PEREIRA, Leonardo Fadul. Análise econômica do direito e pragmatismo jurídico: algumas noções sobre a teoria de Richard A. Posner. In: DIAS, Jean Carlos (org). O pensamento jurídico contemporâneo. Rio de Janeiro: Forense; São Paulo: Método, 2015.

PINHEIRO, Armando Castelar; SADDI, Jairo. Direito, economia e mercados. $2^{\mathrm{a}}$ reimpressão. Rio de Janeiro: Elsevier, 2005.

POSNER, Richard A. A economia da justiça. São Paulo: Martins Fontes, 2010.

2012.

, Richard. A. A problemática da teria moral e jurídica. São Paulo: Martins Fontes,

Richard. A. Economic Analysis of Law. Parte I. Cap. I. New York: Aspen Publishers, 2007.

Richard A. El Análisis Económico del Derecho en el Common Llaw, en el Sistema Romano-Germánico, y en las Naciones en Desarrollo. Revista de Economia. 2005.

Richard A. Maximización de la Riqueza y Tor Law. Una Investigación Filosófica. Disponível em: http://www.eumed.net/cursecon/textos/posner-tort.pdf. Acesso em: 20 jun. 2019.

Richard. A. Problemas de Filosofia do Direito. São Paulo: Martins Fontes, 2007.

RENDEIRO, Carla Blanco. Maximização da riqueza x justiça: a crítica de Dworkin à análise econômica do direito. In: DIAS, Jean Carlos (org). O pensamento jurídico contemporâneo. Rio de Janeiro: Forense; São Paulo: Método, 2015. 
VAZ, Isabel. Direito econômico das propriedades. 2.ed. Rio de Janeiro: Forense, 1993.

VERA, Flávia Santinoni. A Análise Econômica da Propriedade. In: Direito e Economia no Brasil. Org. Luciano Benetti Timm. São Paulo: Atlas, 2018.

Consequências do direito brasileiro para o empreendedorismo. In: Agenda Legislativa. Brasília: Senado Federal, 2011.

VIDAL, Sandra Regina Martini. Propriedade da Terra: análise sócio-jurídica. Porto Alegre: Livraria do Advogado, 2003.

ZYLBERSZTAJN, Decio; SZTAJN, Rachel, (Org.) Direito e Economia. Rio de Janeiro: Campus/Elsevier, 2005. 